\title{
High photobiont diversity in the common European soil crust lichen Psora decipiens
}

\author{
Ulrike Ruprecht • Georg Brunauer • Roman Türk
}

Received: 30 October 2013/Accepted: 25 February 2014/Published online: 8 March 2014

(C) The Author(s) 2014. This article is published with open access at Springerlink.com

\begin{abstract}
The genetic diversity of green algal photobionts (chlorobionts) in soil crust forming lichens was studied as part of the SCIN-project (Soil Crust InterNational). A total of 64 lichen samples were collected from four different sites along latitudinal and altitudinal gradients in Europe (Tabernas/Spain; Hochtor-Großglockner/Austria; Gynge Alvar/ Sweden; Ruine Homburg/Germany). The dominant lichen species at all four sites was Psora decipiens, often occurring with Buellia elegans, Fulgensia bracteata, F. fulgens and Peltigera rufescens. Genetic identification of chlorobionts was carried out using the nuclear marker (nrITS) and a chloroplast marker ( $p s b \mathrm{~L}-\mathrm{J})$. We found $P$. decipiens to be associated with several different species of Trebouxia and Asterochloris, although previously described to only have Asterochloris sp. The phylogenetic analyses revealed a high chlorobiont diversity with 12 well supported clades, including Trebouxia asymmetrica, $T$. jamesii, T. impressa and other, as yet taxonomically unidentified clades (Trebouxia sp. URa1-4, T. sp. URa6, T. sp. URa7-13). Additionally, five clades of Asterochloris were identified (A. magna, A. sp. URa14 -17). Most of the chlorobiont species appeared to be cosmopolitan, but five clades were unevenly distributed between the sampling sites with only Trebouxia being found in the warm and dry Spanish habitats and combinations of Trebouxia and Asterochloris in the cooler and more humid habitats. The wide range of chlorobiont species might contribute to the observed domination of $P$. decipiens at all four research sites of the SCIN project which range from a desert in Spain to an alpine site in the Alps of Austria.
\end{abstract}

Keywords Soil crust forming lichens · Genetic diversity · Chlorobiont · Psora decipiens · Trebouxia sp. · Asterochloris sp.

Communicated by Guest Editors of S.I.: Biocrust.

Electronic supplementary material The online version of this article (doi:10.1007/s10531-014-0662-1) contains supplementary material, which is available to authorized users.

U. Ruprecht $(\bowtie) \cdot$ G. Brunauer · R. Türk

Organismic Biology, University of Salzburg, Hellbrunnerstr. 34, 5020 Salzburg, Austria

e-mail: ulrike.ruprecht@sbg.ac.at 


\section{Introduction}

Large parts of the world are covered by soils with a surface vegetative community of lichens, cyanobacteria, micro fungi, algae and bryophytes, so-called biological soil crusts (BCSs, Fig. 1; Belnap et al. 2001). In the absence of larger, higher plants, lichens, small plants and mosses can stabilize the soil surface against erosion and provide shelter to a broad range of insects and other arthropods (Brantley and Shepherd 2004). BSCs also play an important role in the soil water balance and nutrient cycle (Belnap et al. 2001, 2006; Maestre et al. 2011). At first, BSCs were only described for drylands (arid and semiarid areas) which occupy $41 \%$ of Earth's land area (Adeel et al. 2005), but recently these communities have also been reported in alpine and nival regions (e.g. Türk and Gärtner 2001).

The species composition of BSCs mainly depends on water-availability, climate zone and soil-type (Rosentreter and Belnap 2001). While cyanobacteria dominate soil crusts in hot desert regions, lichens tend to be more abundant in regions with higher precipitation (Belnap et al. 2001). Due to their poikilohydric lifestyle, lichens are very well adapted to extreme habitats with rapid temperature and moisture fluctuations, such as high alpine areas and arid areas with high insolation in southern Europe and other parts of the world (Lange et al. 1997; Lange 2000). BSC-forming lichens are present in different growth forms, crustose, foliose and fruticose, with individual characteristics according to the climate zones (Grube et al. 2010). In particular, crustose lichens like Buellia sp. and closely attached foliose lichens, such as the common Psora sp., form a compact and stable zone in the upper few millimetres of the substratum (Belnap and Lange 2001). The rhizines and rhizomorphs of lichens can stabilize soils more efficiently than cyanobacterial dominated BSC and contribute to a higher amount of soil carbon and nitrogen, soil moisture and plantavailable nutrients (Belnap et al. 2006; Maestre et al. 2011).

Very little is known about either the complexity or basis of the successful strategies of lichens in BSCs despite their world-wide importance (Grube et al. 2010). Because of their slow growth, lichens cannot compete effectively against vascular plants but, in areas with

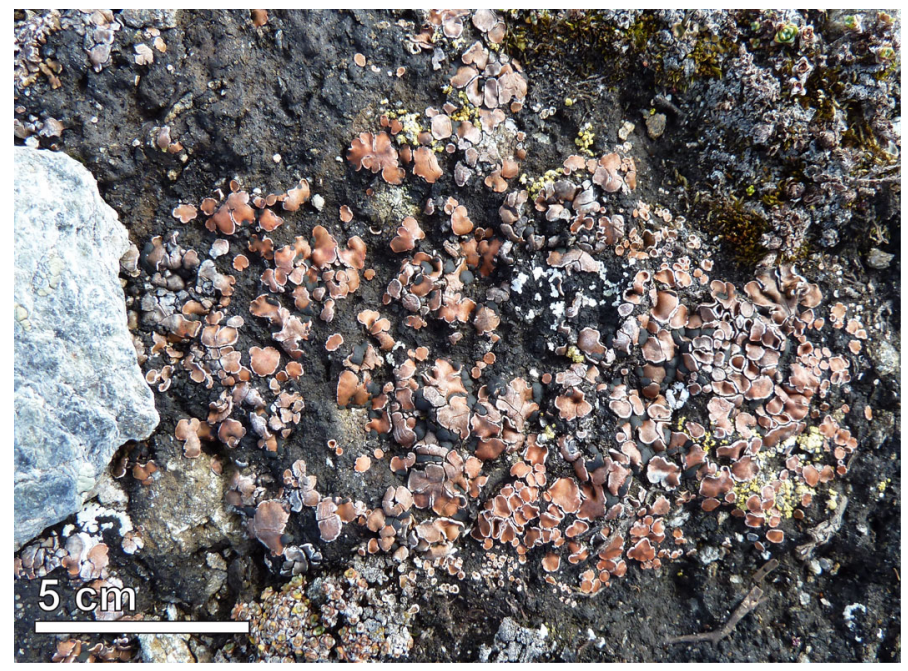

Fig. 1 Typical lichen dominated soil crust in high alpine areas, with Psora decipiens, Fulgensia sp. and mosses 
extreme abiotic conditions such as long periods of drought or cold, higher plants are excluded and lichens fill this important niche (Lalley et al. 2006). The symbiotic life form of lichens is composed of a fungal (mycobiont) and an photosynthetic partner (photobionts), and the latter can be an eukaryotic green alga (chlorobiont) and/or a cyanobacterium (cyanobiont). The ability of mycobionts to switch photobionts (Nelsen and Gargas 2009; Otalora et al. 2010; Henskens et al. 2012) and associate with more than one photobiont species or genotype along a climatic gradient appears to be a mechanism used by lichens to adapt to particular habitats. This has been reported for crustose lichens (Blaha et al. 2006; Muggia et al. 2008; Ruprecht et al. 2012) and for fruticose lichens (Kroken and Taylor 2000). The influence of photobiont selection on the ecological amplitude of lichens is still largely underexplored (Peksa and Skaloud 2011) and shedding more light on this phenomenon would help towards understanding structure, composition and development of BCSs (Bowker 2007; Lazaro et al. 2008).

The research reported here is part of the international and interdisciplinary SCINProject (Soil Crust InterNational; please see Büdel et al. 2014) which focuses on the biodiversity, the ecological roles and functions of BSCs in four different sites which differ substantially from each other in terms of soil composition, sea-level, seasonal temperatures and precipitation.

An important first step is to identify the photobionts that occur in any particular lichen species. The major goal, therefore, of the present study was determining the biodiversity of green algal photobionts (chlorobionts) of the soil crust lichen Psora decipiens by molecular methods. The crustose green-algal lichen P. decipiens (Hedw.) Hoffm. [Lecidea d. (Hedw.) Ach.], to date described as being only associated with Asterochloris sp. (Schaper and Ott 2003), is an important component of BSC at all four SCIN locations and provides an opportunity to investigate photobiont heterogeneity within a widespread lichen species. Molecular analysis of the soil crust lichens' fungal partner is part of another study within the SCIN project. Additionally, we aimed to refine molecular methods to better handle the difficulties that arise in the molecular analysis of soil crust samples because of the presence of multiple organisms.

\section{Materials and methods}

\section{Investigation sites and material}

Sixty-four samples of the key lichen on soil crusts, $P$. decipiens together with other species (see Online Resource 1) were collected at the four investigation sites of the SCIN-Project which cover both latitudinal and altitudinal gradients. For more detailed site descriptions and maps please see Büdel et al. (2014).

1. Tabernas field site, SE Spain $\left(37.0127222^{\circ},-002.4356389^{\circ}\right)$. This area is one of the driest regions in Europe influenced by the semi-arid Mediterranean climate. The mean annual temperature with a wide range is $18.5{ }^{\circ} \mathrm{C}$ and the mean annual precipitation is $220 \mathrm{~mm}$ but highly variable from year to year. The average annual insolation is very high at more than 3,000 h/year. The BCSs cover one third of the area and are dominated by different types of lichens.

2. Hochtor, Großglockner, Alps, Austria $\left(47.0833333^{\circ}, 012.8500000^{\circ}\right)$. This high elevation site, with an altitude of $2,600 \mathrm{~m}$ a.s.1., is influenced by the severe Alpine climate with temperatures around $-9{ }^{\circ} \mathrm{C}$ in January and $3{ }^{\circ} \mathrm{C}$ in July and an annual 
mean of around $-3.0^{\circ} \mathrm{C}$. The annual precipitation is around 2,000 mm/year of which $70 \%$ falls as snow. The BCSc are dominated by lichens together with mainly cyanobacteria and green algae, some bryophytes, and a few vascular plants.

3. Ruine Homburg, Gössenheim, Bavaria, Germany $\left(50.0166667^{\circ}, 009.8000000^{\circ}\right)$. The climate in this area is warm temperate with an annual mean temperature of $9.2{ }^{\circ} \mathrm{C}$ and an annual precipitation of $600 \mathrm{~mm}$. This anthropogenic influenced landscape is covered by a thin vegetation layer (dry grassland) and dominated by cryptogams.

4. Nature Reserve Gynge Alvar, Öland, Sweden $\left(56.5421389^{\circ}, 016.4783889^{\circ}\right)$. This lowest elevation site is located on the island of Öland situated close to the SE coast of Sweden. With an annual mean precipitation of $450 \mathrm{~mm}$ this is the driest area of the whole country. The mean temperature is around $6.5^{\circ} \mathrm{C}$ and ranges from $-2{ }^{\circ} \mathrm{C}$ in February to $17{ }^{\circ} \mathrm{C}$ in July. The BSC dominated zones are covered with cyanobacteria, bryophytes and lichens with infrequent higher plants.

\section{Methods}

DNA-amplification, primer-design, sequencing

Total DNA was extracted from individual thalli by using the DNeasy Plant Mini Kit (Qiagen) according to the manufacturer's instructions. The PCR mix contained 0.5 units of GoTaq DNA polymerase, $0.2 \mathrm{nM}$ of each of the four dNTPs, $0.3 \mu \mathrm{M}$ of each primer (0.6 if degenerated) and about $1 \mathrm{ng}$ genomic DNA. The internal transcribed spacer region (ITS) of the photobionts' nuclear ribosomal DNA (Trebouxia sp. and Asterochloris sp.) and the chloroplast-encoded intergenic spacer psbJ-L (Trebouxia sp.) were amplified and sequenced with the primers described in Tables 1 and 2. Because of soil crust related contaminations - mainly different eukaryotic algae-highly specific primers were developed for amplifying the target markers from Trebouxia sp. and Asterochloris sp. The primers psbF and psbR (Werth and Sork 2010) were used to amplify and sequence the $c p$-marker ( $p s b \mathrm{~L}-\mathrm{J}$ for Trebouxia sp.) from Antarctic samples that were already known to have Trebouxia photobionts (Ruprecht et al. 2012) and from own Trebouxia cultures. These sequences were aligned with relevant $c p$-regions of confirmed related $c p$-genomes from Genbank to design more specific primers. To get sufficient PCR-products nested PCR was performed, first with two outer and rather unspecific primers, followed by a nested reaction with the two newly-developed specific internal primers using a touchdown PCR-protocol (see Table 3). For amplifying Trebouxia ITS we used the primer pairs 18S-ITS-uni-for and ITS4T for the first PCR and ITS1aT and ITS4bT for the nested reaction. For Trebouxia psbL-J the primers for the first reaction were $\mathrm{psbF}$ and $\mathrm{psbR}$ and the nested primers were psbF-sense and psbR-antisense; for Asterochloris-ITS amplification nr-SSU-1780-5' and ITS4 were used for the first reaction and ITS1-sense-A and ITS2-antisense-A for the nested reaction. Several additional algal sequences for Chloroidium sp. and several taxonomically unidentified eukaryotic micro algae species were also amplified and sequenced from soil crust samples using primer combinations ITS1T and ITS4T, ITS1T and ITS1aT, ITS1aT and ITS4aT (primer maps and sequences see Tables 1,2). 


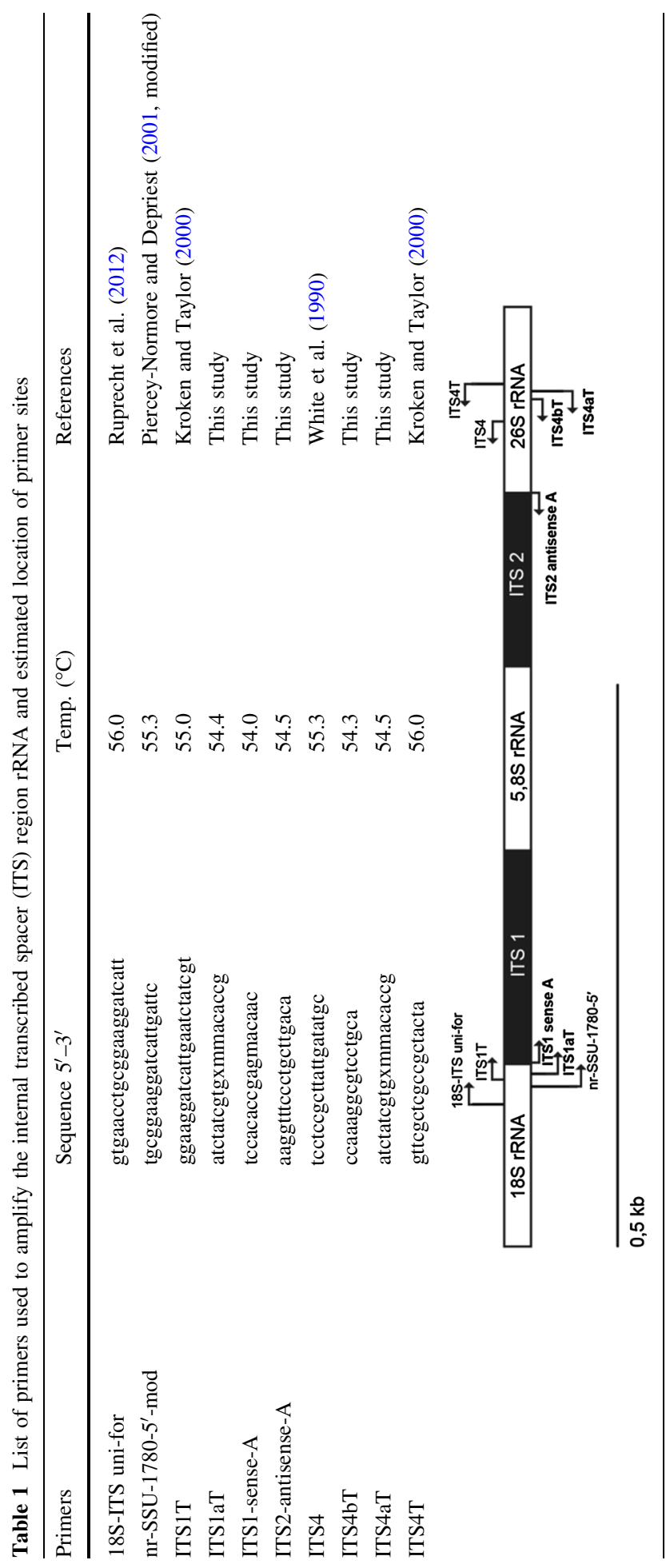




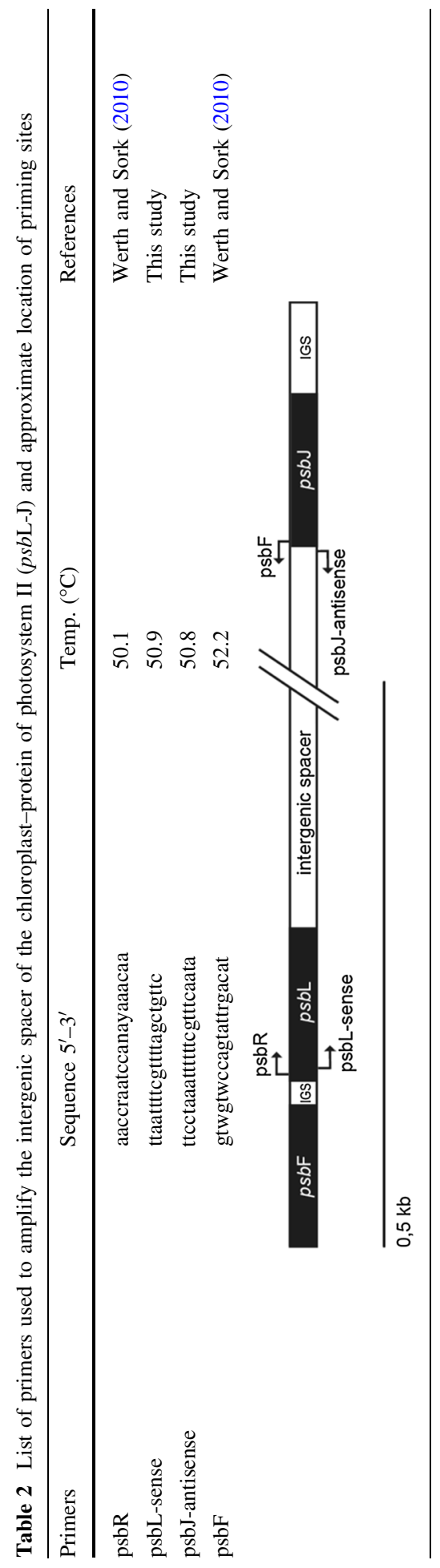




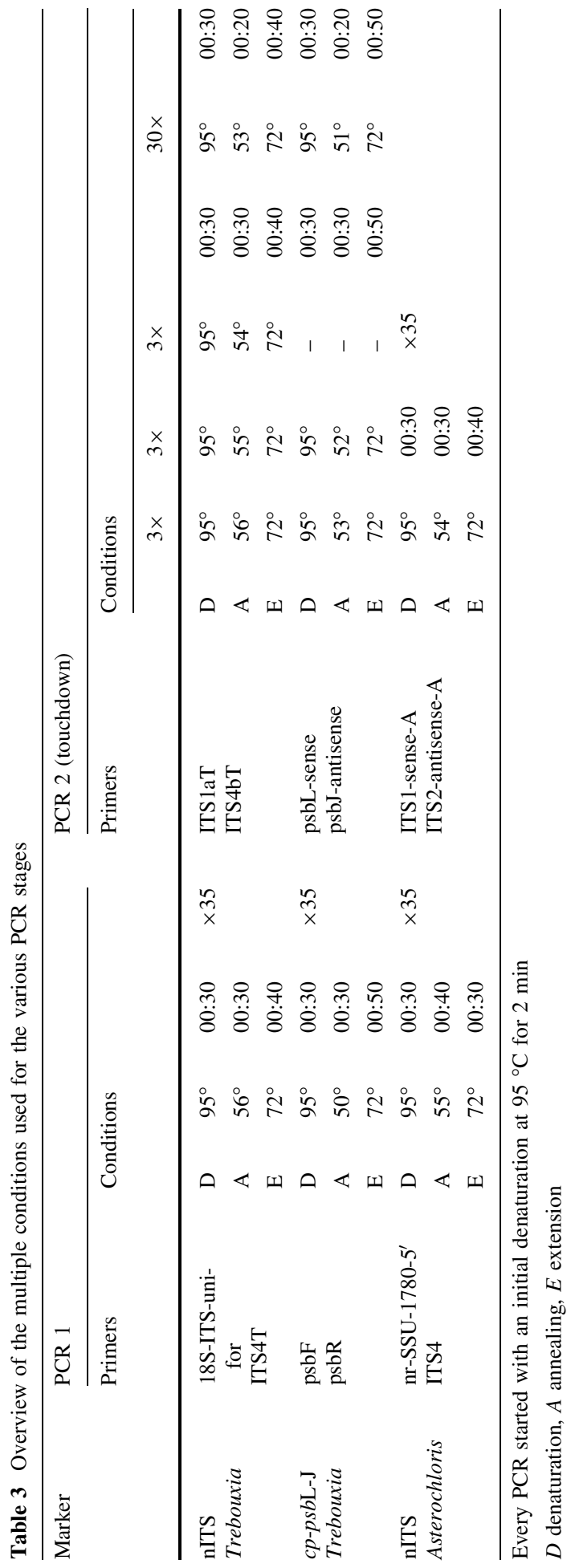


Phylogenetic analysis

Nuclear ITS sequences were assembled and edited using Geneious Pro 5.3.4 (www. geneious.com) and aligned with ClustalW (Thompson et al. 1994). The alignment was subsequently refined by using the MUSCLE algorithm implemented in the Geneious program and the $p s b \mathrm{~L}-\mathrm{J}$-alignment was reworked by hand to correct ambiguously aligned positions. Poorly aligned positions and divergent regions were eliminated from the alignment using Gblocks 0.91b with default settings (Castresana 2000). The congruency of the concatenated Trebouxia-alignment was tested by comparing the topology in the single ITS and the concatenated ITS- $p s b$ F-L trees. Both phylogenies showed similar topologies and the same groups.

Maximum parsimony analyses (MP) were performed using the program PAUP* (Swofford 2003). Heuristic searches with 1,000 random taxon addition replicates were conducted with TBR branch swapping and MulTrees option in operation, equally weighted characters and gaps treated as missing data. Bootstrapping was performed based on 2,000 replicates with random sequence additions. Homoplasy levels were assessed by calculating consistency index $(\mathrm{CI})$, retention index (RI), and rescaled consistency (RC) index from each parsimony search.

Nucleotide substitution models were chosen using JModeltest 2.1.1. (Darriba et al. 2012). The Akaike information criterion selected the GTR model (Rodriguez et al. $1990)+I+\Gamma$ (estimation of invariant sites and a discrete gamma distribution) for the Trebouxia alignments and TRN model (Tamura and Nei 1993) $+\Gamma$ for the Asterochloris alignment as the optimal models. A maximum likelihood analysis (ML) was performed using the program Garli 0.96 (http://www.nescent.org/wg_garli/Main_Page) with the estimated model (GTR $>$ 6rate, $\operatorname{TrN}>010020)$ and default settings. A nonparametric bootstrap was used to assess robustness of clades, running 2,000 pseudoreplicates.

For Bayesian tree inference a Markov Chain Monte Carlo (MCMC) procedure as implemented in the program MrBayes 3.2. was used (Ronquist and Huelsenbeck 2003). The analyses were performed assuming the general time reversible model of nucleotide substitution including estimation of invariant sites and a discrete gamma distribution with six rate categories (GTR $+\mathrm{I}+\Gamma$, Rodriguez et al. 1990). A run with 5 million generations starting with a random tree and employing four simultaneous chains was executed. Every 100th tree was saved into a file. Subsequently, the first $25 \%$ of trees were deleted as the "burn in" of the chain. A consensus topology with posterior probabilities for each clade was calculated from the remaining 37,501 trees.

\section{Results}

The final data matrix of the molecular phylogeny of Trebouxia ITS (see Online Resource 2) comprised 101 OTUs with a length of 431 characters, 226 positions of the alignment were parsimony-informative with the following homoplasy levels $\mathrm{CI}=0.647, \mathrm{RI}=0.953$, $\mathrm{RC}=0.617$. The concatenated Trebouxia ITS/psbL-J (Fig. 2) phylogeny comprised 75 OTUs with 694 characters, 461 positions were parsimony informative and the homoplasy levels amounted $\mathrm{CI}=0.765, \mathrm{RI}=0.958, \mathrm{RC}=0.733$. Finally, the Asterochloris $\mathrm{ITS}$ phylogeny (Fig. 3) comprised 64 OTUs with 435 characters, 169 positions were parsimony informative and the homoplasy levels amounted CI $=0.0907, \mathrm{RI}=0.943, \mathrm{RC}=0.855$. The alignments of Trebouxia ITS and Asterochloris ITS contained several closely related accessions from Genbank including all taxonomically identified and several taxonomically 


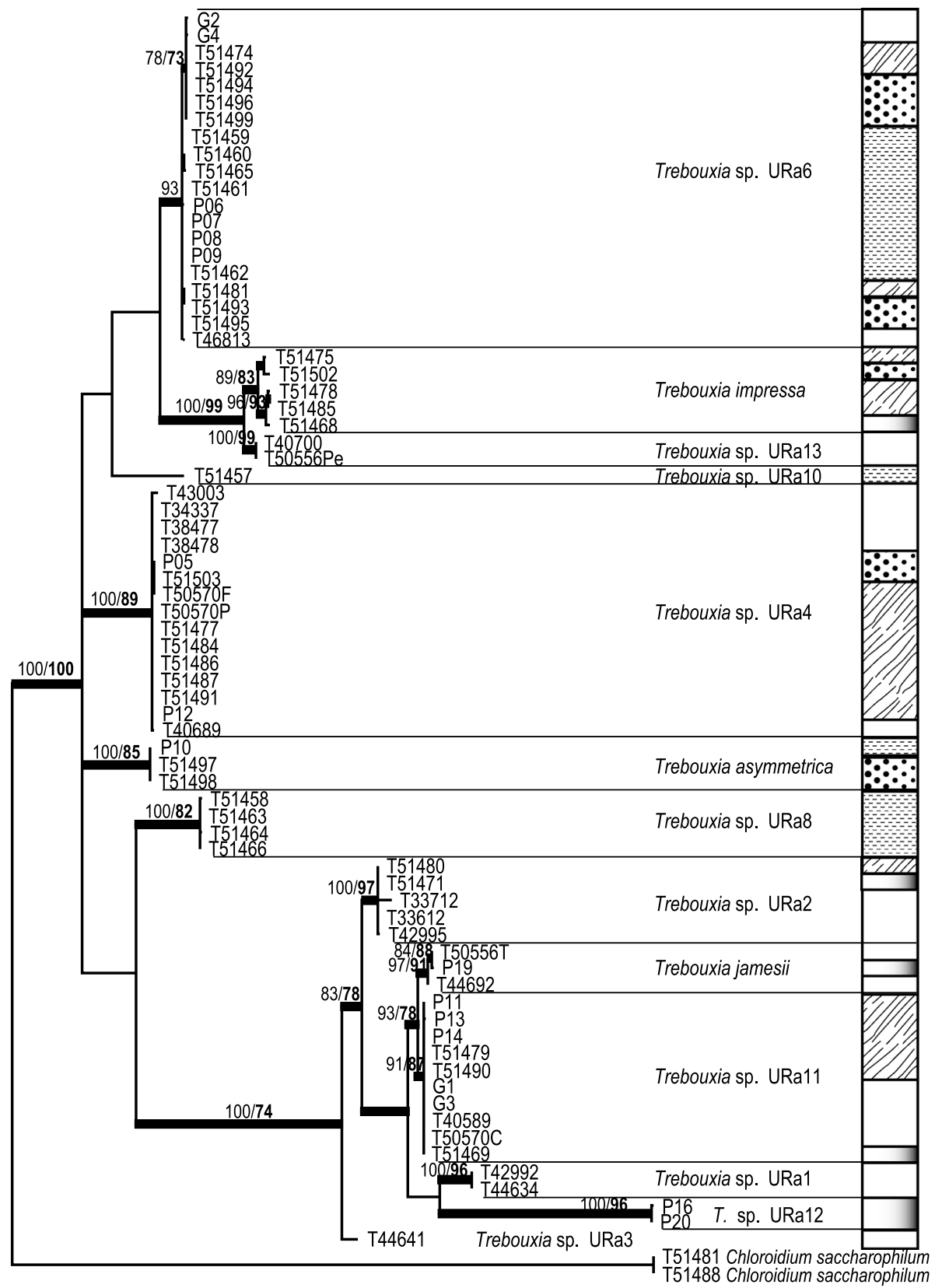

- 5 changes $\quad \mathrm{MP} / \mathrm{ML} /$ MrBayes $>0.93$

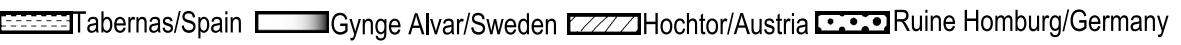

Fig. 2 Phylogeny of concatenated ITS and $p s b$ L-J sequences of Trebouxia specimens from the four SCINsites, combined with own samples from Antarctica and Austria. The bars beside the phylogeny show the provenance of the specimens in the respective habitats. The bootstrap values with $>70$ support of MP and ML analyses were directly mapped on this Bayesian tree with $>0.92$ support (branches in bold) 


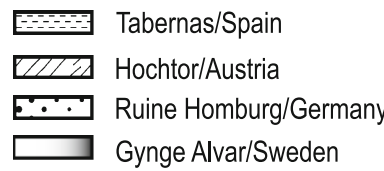

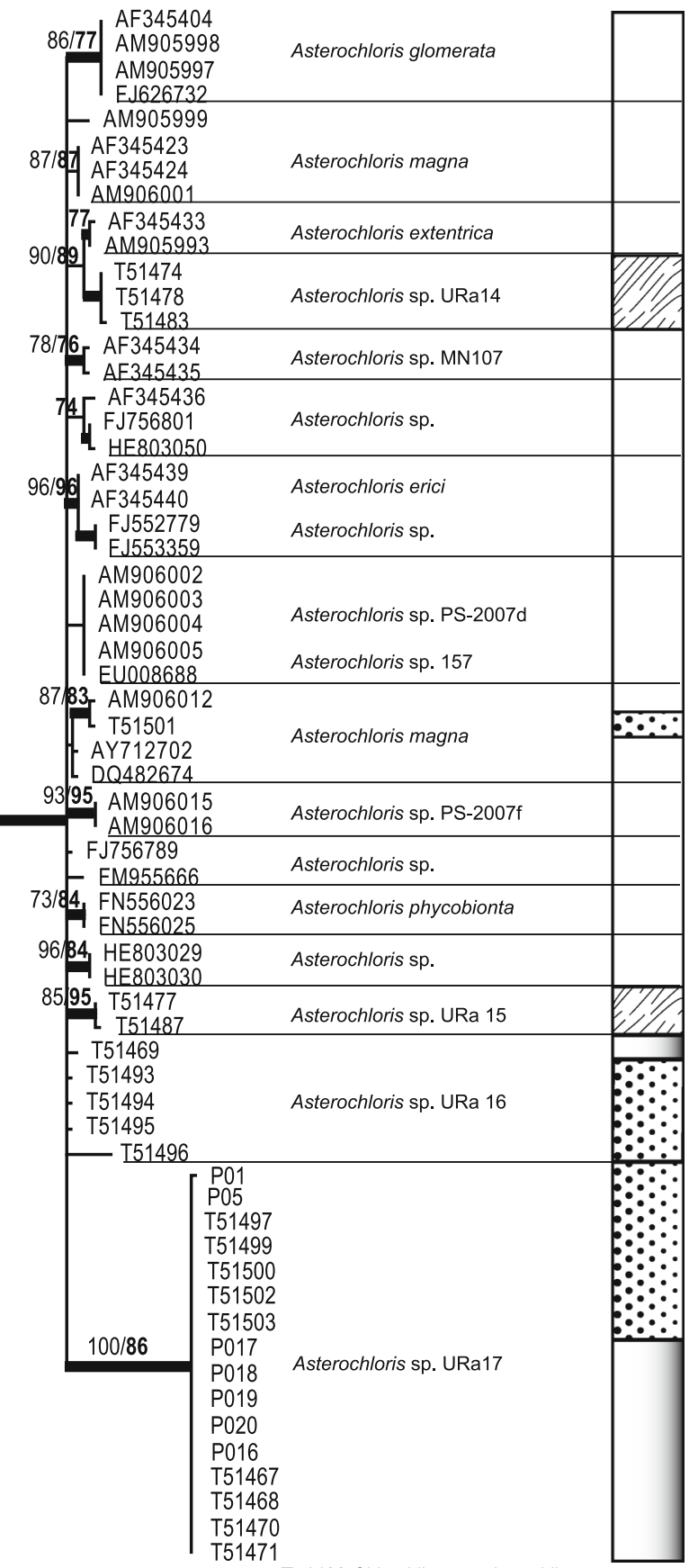


4Fig. 3 Phylogeny of ITS sequences of Asterochloris specimens from the four SCIN-sites, combined with downloaded accessions from Genbank. The bars beside the phylogeny show the provenance of the specimens in the respective habitats. The bootstrap values with $>70$ support of MP and ML analyses were directly mapped on this Bayesian tree with $>0.92$ support (branches in bold)

unidentified species (43 for Trebouxia, 35 for Asterochloris), plus accessions from other high Alpine and Antarctic areas included in order to get information about intra-specific sequence variation and to see whether the species and haplotypes could be assigned to known clades. Information about the samples is summarized in Online Resource 1.

The ML and Bayesian analyses recovered the same well-supported clades as the MP analysis. The Bayesian consensus trees, with the support values of all three analyses are shown in Online Resource 2 and Figs. 2 and 3. The plotted bars beside the trees show the sample provenance (see also Table 4).

\section{Phylogenetic analysis}

\section{Trebouxia ITS (Online Resource 2)}

This phylogenetic reconstruction was performed to get an overview of the relationship between the photobionts from soil crust lichens and other, already published, sequences of Trebouxia species. It revealed 16 well supported, monophyletic groups of which 12 are part of this study and several weakly supported clades of Trebouxia photobionts. The tree was rooted with Chloroidium saccharophilum the closest related algal group. In addition to the already well known Trebouxia species ( $T$. showmanii, $T$. gigantea, T. asymmetrica, $T$. arboricola, $T$. decolorans, $T$. jamesii, $T$. impressa) and other published but taxonomically unidentified clades ( $T$. sp. URa1-4, T. sp. URa6 resp. T. sp. Guzow, etc.), several other clades appeared. The backbone was not well supported and therefore the topology of the different clades to each other will not be discussed.

A new and well-supported group with four accessions occurred only in Tabernas and was closely related to T. gigantea.T. asymmetrica, which contained two accessions from Ruine Homburg, was a sister to clade $T$. sp. URa4 found in several accessions from Hochtor as well as from Ruine Homburg.

Another new group ( $T$. sp. URa11), formed by several accessions from Hochtor and Gynge Alvar, was sister to T. jamesii and to the endemic group of Antarctic photobionts found in extremely cold and dry regions ( $T$. sp. URa1) as well as to a new and strongly supported clade of two Swedish samples (T. sp. URa12).

The heterogeneous clade of T. impressa formed a well-supported group and contained samples from Ruine Homburg, Hochtor and Gynge Alvar, together with its strongly supported sister clade of two accessions including two samples which are not from the study areas (high alpine areas in Austria, T. sp. URa13).

Trebouxia sp. URa6 which included several specimens from Tabernas, Hochtor and Ruine Homburg, was only weakly supported and, finally, T. sp. URa2 that frequently occurs in Antarctica was placed together with one accession from Hochtor and one from Gynge Alvar.

\section{Concatenated Trebouxia ITS and psbL-J (Fig. 2)}

This phylogeny, including concatenated sequences of nuclear ITS and the intergenic spacer of the chloroplast-protein of photosystem II ( $p s b \mathrm{~L}-\mathrm{J})$, produced the same groupings as the 
Trebouxia ITS, but they were more strongly supported and better resolved (see $T$. sp. URa2, 4 and 6). The backbone was better structured and several clades clustered clearly together in one well supported subgroup (T. sp. URa2, T. jamesii, T. sp. URa11, T. sp. URa1, T. sp. URa12 and T. sp. URa3).

\section{Asterochloris ITS (Fig. 3)}

Finally, the phylogenetic reconstruction of the nuclear ITS of Asterochloris samples including several accessions from Genbank showed many low diverged, but well supported and, in the literature described, species (Peksa and Skaloud 2011). The tree was rooted with $C$. saccharophilum and $T$. impressa in order to better see the degree of relationship of the different photobiont groups. The backbone in this phylogeny was not supported. A quite distinct, strongly supported and new clade contained the majority of Asterochloris accessions from this study coming from Ruine Homburg and Gynge Alvar. Two other well, and one weakly, supported groups contained the remaining accessions from Ruine Homburg, Hochtor and Gynge Alvar. Only one sample, from Ruine Homburg, clustered together with A. magna. No Asterochloris sequence was detected from Tabernas.

The summarized phylogenetic results for photobionts showed three delimited algal groups (Asterochloris, Chloroidium and Trebouxia) and several other, but not assignable eukaryotic green micro algae (see Table 4). Five different Asterochloris clades occurred in high alpine and temperate regions (Hochtor, Ruine Homburg and Gynge Alvar) but none at the hot and arid Tabernas field site in SE-Spain. Only one species of Chloroidium sp. was molecularly identified and occurred at Hochtor. Trebouxia was represented by 12 different clades (including two specimens from outside the SCIN-area at Hochtor [T. sp. URa13]), and was found to occur in all habitats. Most of the photobionts were cosmopolitan (12 clades) and only a few accessions forming five small groups were restricted to single sample sites (Asterochloris sp. URa14, A. sp. URa15-Hochtor; Trebouxia sp. URa8abernas; T. sp. URa12-Gynge Alvar; T. sp. URa13-Hochtor).

The key lichen $P$. decipiens occurred not only at all SCIN habitats but also in all additional soil crust specimens from other high Alpine areas. In most cases each individual lichen specimen contained one or more photobionts from every clade together with other eukaryotic green micro algae (EGMA; see Online Resource 1).

The species specificity of the mycobiont towards its photobiont was quite low for $P$. decipiens. In contrast, Fulgensia bracteata ssp. deformis (which has so far only been found

Table 4 Overview of chlorobiont occurrence in the four SCIN habitats

\begin{tabular}{|c|c|c|c|c|c|}
\hline & Genus & $\begin{array}{l}\text { Tabernas/ } \\
\text { Spain }\end{array}$ & $\begin{array}{l}\text { Hochtor/ } \\
\text { Austria }\end{array}$ & $\begin{array}{l}\text { Ruine } \\
\text { Homburg/ } \\
\text { Germany }\end{array}$ & $\begin{array}{l}\text { Gynge/ } \\
\text { Sweden }\end{array}$ \\
\hline \multirow{4}{*}{$\begin{array}{l}\text { Clades/ } \\
\text { species }\end{array}$} & Asterochloris sp. & - & 2 & 3 & 2 \\
\hline & $\begin{array}{l}\text { Chloroidium } \\
\text { saccharophilum }\end{array}$ & - & 1 & - & - \\
\hline & Trebouxia sp. & 4 & 5 & 5 & 5 \\
\hline & Other EGMA & - & 4 & 7 & 2 \\
\hline
\end{tabular}

Other EGMA other eukaryotic green micro algae 
in samples from Hochtor) only occurred with $T$. sp. URa4 and $A$. sp. URa15 (the latter until now only known from this area, Figs. 2, 3). Peltigera rufescens, known to have a cyanobacterium as its primary photobiont (O'Brien et al. 2005), was also found to be associated with chlorobionts (Henskens et al. 2012). Specimens of P. rufescens from Ruine Homburg were associated with $T$. sp. URa6 and $A$. sp. URa16, although other chlorobionts were available at the site; at Hochtor $P$. rufescens was found with $T$. impressa (see Online Resource 1, Figs. 2, 3).

\section{Discussion}

This evaluation of European lichen-dominated soil crusts from four geographically and climatically diverse sites revealed an unexpectedly high diversity of photobionts in association with the dominant lichen P. decipiens. Until now, only the genus Asterochloris has been described as the photobiont of $P$. decipiens (Schaper and Ott 2003), but we detected 12 different groups of the genus Trebouxia as well as other eukaryotic green micro algae like $C$. saccharophilum. Several of these micro algae are already known to exist as lichen photobionts, such as T. impressa, T. asymmetrica or the, as yet undescribed, Trebouxia sp. URa2, URa4, URa6. The latter three species have also been identified as photobionts from crustose lichens (Ruprecht et al. 2012). Other Trebouxia species that are known as freeliving algae (e.g. T. arboricola; Ettl and Gärtner 1995) were included in the analysis but not found in the soil-crust samples. P. decipiens at Hochtor showed a shared use of the available photobionts with other lichen species that were present (see Online Resource 1) with each species having a different level of specificity towards to its photobiont. We can conclude for $P$. decipiens that this lichen is not limited to a single species or even genus of photobiont but instead associates with a broad range of apparently locally available algae. The low specificity of $P$. decipiens for its photobiont might contribute to the broad ecological amplitude of this lichen, a possibility already described for other lichens (Blaha et al. 2006).

Most photobiont species, especially from the genus Trebouxia, are cosmopolitan with more or less broad ecological preferences (Fernandez-Mendoza et al. 2011; Ruprecht et al. 2012) and this was true for the most commonly detected clades in this study. However, several distinct and strongly supported clades of the genera Asterochloris and Trebouxia (Online Resource 2, Figs. 2, 3) do not seem to be cosmopolitan, e.g. T. sp URa8 which, to date, has only been found at Tabernas. This clade is sister to T. gigantea, a photobiont which is widely distributed in temperate habitats (Ettl and Gärtner 1995). This is a somewhat similar situation to that found in another study of the cosmopolitan photobiont $T$. jamesii. Ruprecht et al. (2012) which showed that one sub-clade was only present in the most extreme habitat of the cold deserts in the Darwin Area (Antarctica). More investigations with much more extended taxon sampling needs to be done in order to decide which adaptations have occurred in response to extreme climatic conditions or particular ecological niches, and which speciation model applies.

Although no special ecological preferences are described in the literature for the genus Asterochloris (Peksa and Skaloud 2011), no representatives of this genus were found at the Tabernas desert in SE-Spain. Asterochloris species were, however, present at the more temperate and high alpine areas. There are at least two possible interpretations for these findings: Either the Asterochloris photobionts of $P$. decipiens cannot cope with the desert climate or the $P$. decipiens present at Tabernas preferentially selects other photobiont 
species. Attempting to answer this question is part of another study within the framework of the SCIN-project.

The highly variable occurrence of different photobiont types in association with the same mycobiont, $P$. decipiens, across all sampled habitats supports the opinion that flexibility in photobiont choice may influence the ecological amplitude of lichens (Peksa and Skaloud 2011). Low photobiont specificity is already known for several lichen species that show a wide ecological amplitude, e.g. Lecanora rupicola, and it appears that the key BSC lichen $P$. decipiens might employ a similar strategy for colonizing highly diverse habitats. In addition, the improved molecular techniques developed here can be important tools for future surveys of photobionts. Our results provide basic information that can underpin conservation measures to protect this highly specialized and diverse community of organisms that colonises and protects the soil surface in large areas of the world.

Acknowledgments We are very thankful to Prof. T.G. Allan Green (Universidad Complutense Madrid) for advice and support. This study is part of the SCIN-project (Soil Crust InterNational-Understanding and valuing biological soil protection of disturbed and open land surfaces, http://www.soil-crust-international. org/) and was financially supported by the Austrian Science Fund (FWF): I_00798-B16, Partner 3: Prof. Thomas Peer (University of Salzburg).

Open Access This article is distributed under the terms of the Creative Commons Attribution License which permits any use, distribution, and reproduction in any medium, provided the original author(s) and the source are credited.

\section{References}

Adeel Z, Safriel U, Niemeijer D, White R (2005) Millennium ecosystem assessment. Ecosystems and human well-being:desertification synthesis. World Resources Institute, Washington, DC

Belnap J, Lange OL (eds) (2001) Biological soil crusts: structure, function, and management, vol 150. Ecological studies. Springer-Verlag, Berlin

Belnap J, Büdel B, Lange OL (2001) Biological soil crusts: characteristics and distribution. In: Belnap J, Lange OL (eds) Biological soil crusts: structure, function, and management, vol 150. Ecological studies. Springer-Verlag, Berlin, pp 3-30

Belnap J, Phillips SL, Troxler T (2006) Soil lichen and moss cover and species richness can be highly dynamic: The effects of invasion by the annual exotic grass Bromus tectorum, precipitation, and temperature on biological soil crusts in SE Utah. Appl Soil Ecol 32(1):63-76

Blaha J, Baloch E, Grube M (2006) High photobiont diversity associated with the euryoecious lichenforming ascomycete Lecanora rupicola (Lecanoraceae, Ascomycota). Biol J Linn Soc 88(2):283-293

Bowker MA (2007) Biological soil crust rehabilitation in theory and practice: an underexploited opportunity. Restor Ecol 15(1):13-23

Brantley SL, Shepherd UL (2004) Effect of cryptobiotic crust type on microarthropod assemblages in pinonjuniper woodland in central New Mexico. West North Am Nat 64(2):155-165

Büdel B, Colesie C, Green TGA, Grube M, Lázaro Suau R, Loewen-Schneider K, Maier S, Peer T, Pintado A, Raggio J, Ruprecht U, Sancho LG, Schroeter B, Türk R, Weber B, Wedin M, Westberg M, Williams L, Zheng L (2014) Improved appreciation of the functioning and importance of biological soil crusts in Europe - the Soil Crust International project (SCIN). Biodivers Conserv

Castresana J (2000) Selection of conserved blocks from multiple alignments for their use in phylogenetic analysis. Mol Biol Evol 17(4):540-552

Darriba D, Taboada GL, Doallo R, Posada D (2012) jModelTest 2: more models, new heuristics and parallel computing. Nat Methods 9(8):772

Ettl H, Gärtner G (1995) Syllabus der Boden-Luft- und Flechtenalgen. Gustav Fischer, Stuttgart

Fernandez-Mendoza F, Domaschke S, Garcia MA, Jordan P, Martin MP, Printzen C (2011) Population structure of mycobionts and photobionts of the widespread lichen Cetraria aculeata. Mol Ecol 20(6):1208-1232 
Grube M, Rabensteiner J, Grube U, Muggia L (2010) Architectures of biocomplexity; lichen-dominated soil crusts and mats. In: Seckbach J, Oren A (eds) Microbial mats: modern and ancient microorganisms in stratified systems. Springer, London, pp 341-357

Henskens FL, Green TGA, Wilkins A (2012) Cyanolichens can have both cyanobacteria and green algae in a common layer as major contributors to photosynthesis. Ann Bot Lond 110(3):555-563

Kroken S, Taylor JW (2000) Phylogenetic species, reproductive mode, and specificity of the green alga Trebouxia forming lichens with the fungal genus Letharia. Bryologist 103(4):645-660

Lalley JS, Viles HA, Henschel JR, Lalley V (2006) Lichen-dominated soil crusts as arthropod habitat in warm deserts. J Arid Environ 67(4):579-593

Lange OL (2000) Die Lebensbedingungen von Bodenkrusten-Organismen: Tagesverlauf der Photosyntese einheimischer Erdflechten*). Hoppea, Denkschr Regensb Bot Ges 61:423-443

Lange OL, Belnap J, Reichenberger H, Meyer A (1997) Photosynthesis of green algal soil crust lichens from arid lands in southern Utah, USA: role of water content on light and temperature responses of $\mathrm{CO}_{2}$ exchange. Flora 192:1-15

Lazaro R, Canton Y, Sole-Benet A, Bevan J, Alexander R, Sancho LG, Puigdefabregas J (2008) The influence of competition between lichen colonization and erosion on the evolution of soil surfaces in the Tabernas badlands (SE Spain) and its landscape effects. Geomorphology 102(2):252-266

Maestre FT, Bowker MA, Canton Y, Castillo-Monroy AP, Cortina J, Escolar C, Escudero A, Lazaro R, Martinez I (2011) Ecology and functional roles of biological soil crusts in semi-arid ecosystems of Spain. J Arid Environ 75(12):1282-1291

Muggia L, Grube M, Tretiach M (2008) Genetic diversity and photobiont associations in selected taxa of the Tephromela atra group (Lecanorales, lichenised Ascomycota). Mycol Prog 7(3):147-160

Nelsen MP, Gargas A (2009) Symbiont flexibility in Thamnolia vermicularis (Pertusariales: Icmadophilaceae). Bryologist 112(2):404-417

O'Brien HE, Miadlikowska J, Lutzoni F (2005) Assessing host specialization in symbiotic cyanobacteria associated with four closely related species of the lichen fungus Peltigera. Eur J Phycol 40(4):363-378

Otalora MAG, Martinez I, O’Brien H, Molina MC, Aragón G, Lutzoni F (2010) Multiple origins of high reciprocal symbiotic specificity at an intercontinental spatial scale among gelatinous lichens (Collemataceae, Lecanoromycetes). Mol Phylogenet Evol 56(3):1089-1095

Piercey-Normore MD, Depriest PT (2001) Algal switching among lichen symbioses. Am J Bot 88(8):1490-1498

Peksa O, Skaloud P (2011) Do photobionts influence the ecology of lichens? A case study of environmental preferences in symbiotic green alga Asterochloris (Trebouxiophyceae). Mol Ecol 20(18):3936-3948

Rodriguez F, Oliver JL, Marin A, Medina JR (1990) The general stochastic-model of nucleotide substitution. J Theor Biol 142(4):485-501

Ronquist F, Huelsenbeck JP (2003) MrBayes 3: Bayesian phylogenetic inference under mixed models. Bioinformatics 19(12):1572-1574

Rosentreter R, Belnap J (2001) Biological soil crusts of North America. In: Belnap J, Lange OL (eds) Biological soil crusts: structure, function, and management. Springer-Verlag, Berlin, pp 31-50

Ruprecht U, Brunauer G, Printzen C (2012) Genetic diversity of photobionts in Antarctic lecideoid lichens from an ecological viewpoint. Lichenologist 44(5):661-678

Schaper T, Ott S (2003) Photobiont selectivity and interspecific interactions in lichen communities. I. Culture experiments with the mycobiont Fulgensia bracteata. Plant Biol 5(4):441-450

Swofford DL (2003) PAUP*. Phylogenetic analysis using parsimony (* and other methods). Sinauer Associates, Sunderland

Tamura K, Nei M (1993) Estimation of the number of nucleotide substitutions in the control region of mitochondrial-DNA in humans and chimpanzees. Mol Biol Evol 10(3):512-526

Thompson JD, Higgins DG, Gibson TJ (1994) CLUSTAL-W-improving the sensitivity of progressive multiple sequence alignment through sequence weighting, position-specific gap penalties and weight matrix choice. Nucleic Acids Res 22(22):4673-4680

Türk R, Gärtner G (2001) Biological soil crusts of the subalpine, alpine and nival areas in the Alps. In: Belnap J, Lange O (eds) Biological soil crusts: structure, function, and management. Springer-Verlag, Berlin, pp 67-73

Werth S, Sork VL (2010) Identity and genetic structure of the photobiont of the epiphytic lichen Ramalina menziesii on three oak species in Southern California. Am J Bot 97(5):821-830

White TJ, Bruns TD, Lee SB, Taylor JW (1990) Amplification and direct sequencing of fungal ribosomal genes for phylogenies. In: Innis MA, Gelfand DH, Sninsky JJ, White TJ (eds) PCR protocols: a guide to methods and applications. Academic Press, San Diego, p 315-322 